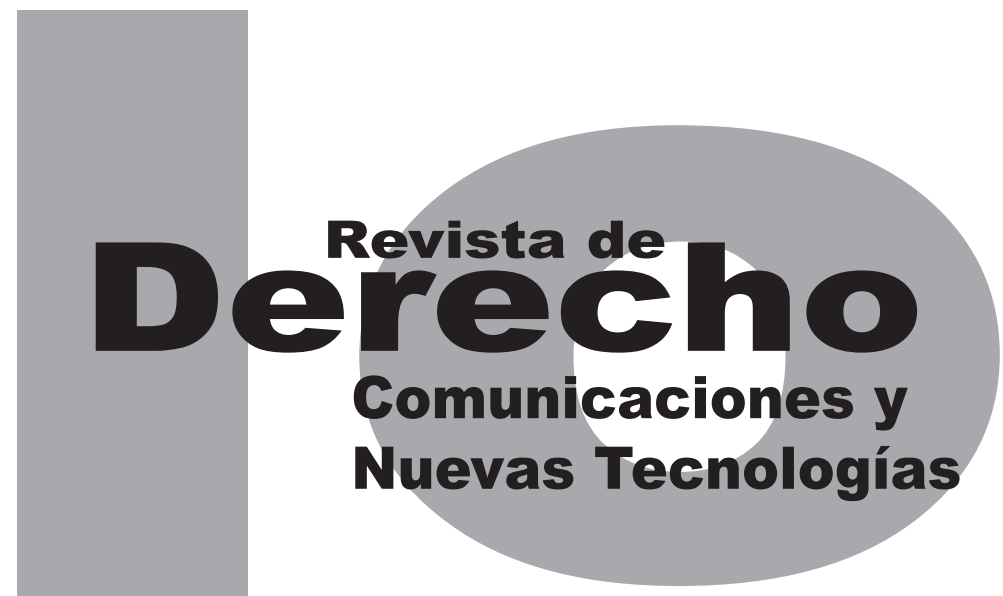

UBER: LA PLATAFORMA TECNOLÓGICA QUE ROMPE CON LOS ESQUEMAS TRADICIONALES DE LA REGULACIÓN EN MATERIA DE TRANSPORTE INDIVIDUAL DE PASAJEROS EN COLOMBIA

\author{
SARA OROzCo Palacio \\ manuela Velásquez Fernández \\ Artículo de revisión \\ DOI: http://dx.doi.org/10.15425/redecom.14.2015.04 \\ Universidad de los Andes \\ Facultad de Derecho \\ Rev. derecho comun. nuevas tecnol.
}

No. 14, julio - diciembre de 2015. ISSN 1909-7786 


\title{
Uber: la plataforma tecnológica que rompe con los esquemas tradicionales de la regulación en materia de transporte individual de pasajeros en Colombia
}

\section{Resumen}

El gobierno colombiano, al igual que otros gobiernos del mundo, está enfrentado a una serie de retos en cuanto a la adaptación de su legislación a las necesidades de los consumidores actuales. Lo anterior se ve reflejado en el surgimiento casi instantáneo de nuevos mercados y en la incapacidad de adaptación de las normas a estas nuevas realidades. La llegada de Uber a Colombia es un claro ejemplo de transformación de mercados y de ruptura de la regulación vigente en materia de transporte. El presente artículo propone una respuesta, desde la óptica del derecho de la competencia, al problema que enfrenta esta plataforma tecnológica en nuestro país. La prohibición no es una salida adecuada. Por el contrario, Uber y el libre juego de oferta y demanda son capaces de crear condiciones de competencia perfecta y servicios de calidad en el transporte individual de pasajeros.

Palabras clave: Uber, plataforma tecnológica, servicio público de transporte terrestre automotor individual de pasajeros, regulación, libre participación de las empresas en el mercado, bienestar del consumidor, eficiencia económica.

\section{Uber: the technological platform that breaks with traditional schemes of regulation in matters relating to individual passenger transport in Colombia}

\begin{abstract}
The Colombian government, like other governments around the world, is facing a number of challenges in adapting their legislation to the needs of today's consumers. This is reflected in the almost instantaneous emergence of new markets and the inability to adapt the rules to these new realities. The arrival of Uber to Colombia is a clear example of the transformation of the market and the rift in current transport regulations. This article proposes an answer, from a competition/antitrust law standpoint, to the problem that this technological platform faces in our country. The ban is not a suitable solution. On the contrary, Uber and the free interaction between supply and demand are capable of creating conditions of perfect competition and quality services in the individual passenger transportation market.
\end{abstract}

Key words: Uber, technological platform, public automotive transportation passenger services, regulation, free participation of enterprises in the market, consumer welfare, economic efficiency.

\section{Uber: a plataforma tecnológica que rompe com os esquemas tradicionais da regulação em matéria de transporte individual de passageiros na Colômbia}

\section{Resumo}

O governo colombiano, igual que outros governos do mundo, está enfrentando a uma série de desafios sobre a adaptação de sua legislação às necessidades dos consumidores atuais. 0 anterior se vê refletido no surgimento quase instantâneo de novos mercados e na incapacidade de adaptação das normas a estas novas realidades. A chegada do Uber na Colômbia é um claro exemplo de transformação de mercados e de ruptura da regulação vigente em matéria de transporte. 0 presente artigo propõe uma resposta, desde a ótica do direito da competência, ao problema que enfrenta esta plataforma tecnológica em nosso país. A proibição não é uma saída adequada. Pelo contrário, Uber e o livre jogo de oferta e demanda, são capazes de criar condições de competência perfeita e serviços de qualidade no transporte individual de passageiros.

Palavras-chave: Uber, plataforma tecnológica, serviço público de transporte terrestre automotor individual de passageiros, regulação, livre participação das empresas no mercado, bem-estar do consumidor, eficiência econômica. 


\title{
Uber: la plataforma tecnológica que rompe con los esquemas tradicionales de la regulación en materia de transporte individual de pasajeros en Colombia*
}

\author{
Sara Orozco Palacio** \\ Manuela Velásquez Fernández ${ }^{* * *}$
}

\section{SUMARIO}

Introducción - I. SERVICIO PÚBLICO DE TRANSPORTE TERRESTRE AUTOMOTOR INDIVIDUAL DE PASAJEROS EN VEHÍCULOS TAXI - A. Breve recuento histórico - II. REGULACIÓN DEL SERVICIO PÚBLICO DE TRANSPORTE TERRESTRE AUTOMOTOR INDIVIDUAL DE PASAJEROS EN VEHÍCULOS TAXI - A. Ley 105 de 1993 - B. Ley 336 de 1996 - C. Decreto 172 de 2001 - III. CARACTERÍSTICAS DEL SERVICIO PÚBLICO DE TRANSPORTE TERRESTRE AUTOMOTOR INDIVIDUAL DE PASAJEROS EN VEHÍCULOS TAXI EN LA CIUDAD DE BOGOTÁ - A. Generalidades - B. Cupos - C. Actores del mercado - 1. Oferentes del servicio - 1.1. Los conductores y propietarios - 1.2. Empresas - 2. Demandantes del servicio - IV. SERVICIO PÚBLICO DE TRANSPORTE TERRESTRE AUTOMOTOR ESPECIAL - V. PANORAMA ACTUAL - VI. UBER - A. Uber en Colombia - B. Posición del Estado - C. Posición de Uber - D. La deficiente y obsoleta regulación del servicio - E. ¿Competencia desleal? - VII. ANÁLISIS ECONÓMICO - A. Deficiencia de los taxis frente al mercado de competencia perfecta - B. Uber en el mercado - VIII. PROPUESTA Y CONCLUSIONES - Referencias.

\footnotetext{
* Cómo citar este artículo: Orozco Palacio, S. y Velásquez Fernández, M. (Diciembre, 2015). UBER: la plataforma tecnológica que rompe con los esquemas tradicionales de la regulación en materia de transporte individual de pasajeros en Colombia. Revista de Derecho, Comunicaciones y Nuevas Tecnologías, 14. Universidad de los Andes (Colombia).

** Abogada de la Universidad de los Andes. Actualmente, abogada asociada de Lloreda Camacho \& Co. Correo: sariso90@hotmail.com

*** Abogada de la Universidad de los Andes. Actualmente, abogada asistente de Suma Legal S.A.S. Correo: manuelavelasquezfernandez@gmail. com
} 
Introducción

El transporte público ha evolucionado a lo largo de la historia, ya sea para satisfacer las necesidades de los consumidores, o para adaptarse a nuevas tecnologías que permiten la prestación del servicio en mejores condiciones de calidad, acceso y seguridad. En esa medida, los gobiernos se han enfrentado a constantes retos y debates frente a la necesidad de regular o no estos servicios, teniendo en cuenta que el transporte es un aspecto fundamental para el desarrollo económico y social de un país.

En Colombia, el transporte ha sido considerado como:

Una actividad indispensable para la vida en sociedad y en particular para las relaciones económicas, que conlleva movilizar personas o cosas de un lugar a otro, mediante diferentes medios. Dichos traslados pueden efectuarse dentro del marco de las relaciones privadas, bajo el amparo de la libertad de locomoción (art. 24 Const.), o ejerciendo actividades económicas dirigidas a obtener beneficios por la prestación del servicio (art. 333). (CConst., C-033/14, N. Pinilla).

Así pues, este servicio ha sido regulado mediante diferentes disposiciones, dentro de las cuales se encuentran normas generales como la Ley 105 de 1993, la Ley 336 de 1996 y la Ley 796 de 2002. Por otra parte, se han expedido normas particulares respecto del Servicio Público de Transporte Terrestre Automotor Individual de Pasajeros en Vehículos Taxi (Decreto 172 de 2001) y del Servicio Público de Transporte
Terrestre Automotor Especial (Decreto 348 de 2015, que derogó el Decreto 174 de 2001).

Teniendo en cuenta que la tecnología avanza más rápido que la ley, y que nos encontramos en un mundo donde los mercados surgen y se transforman de manera instantánea e imprevisible, las normas tienden a volverse obsoletas e ineficaces ${ }^{1}$ en periodos de tiempo demasiado cortos. Colombia no ha sido ajena a esta situación. La llegada de Uber ${ }^{2}$ rompió con los esquemas tradicionales del mercado y la regulación existente en materia de transporte en nuestro país. En ese sentido, cabría preguntarse si las plataformas tecnológicas como Uber deberían contar con un marco regulatorio general, en donde estas puedan operar conforme al libre juego de la oferta y la demanda, o si por el contrario se debería prohibir la prestación del servicio de transporte mediante la interacción de oferta y demanda que dichas plataformas tecnológicas permiten.

El presente escrito propone una alternativa o solución a la problemática que enfrenta Uber en Colombia. Consideramos que Uber no debe ser catalogado ni regulado como una empresa prestadora de servicios de transporte. Por el contrario, lo que se debería hacer es fijar una serie de condiciones generales, bajo las cuales esta plataforma y todas aquellas que conecten

\footnotetext{
1 El problema de la eficacia de una norma se refiere a si la norma es o no cumplida por las personas a quienes se dirige, es decir, los destinatarios (Bobbio, 2007, pág. 30).

2 Para efectos del presente escrito se considerará a Uber como una plataforma tecnológica que conecta oferentes y demandantes del servicio de transporte, como se explicará en profundidad posteriormente.
} 
oferentes y demandantes del servicio de transporte puedan operar legal y libremente, favoreciendo los principios del derecho de la competencia: libre participación de las empresas en el mercado, bienestar del consumidor y eficiencia económica.

Para cumplir con los objetivos planteados anteriormente, el presente escrito se desarrollará de la siguiente manera:

En primer lugar, se explicará en qué consiste el Servicio Público de Transporte Terrestre Automotor Individual de Pasajeros en Vehículos Taxi, se hará un breve recuento histórico, se enunciarán las leyes que regulan la materia, se mencionarán sus características, y se abordará la regulación correspondiente al Servicio Público de Transporte Terrestre Automotor Especial. Esto con el fin de mostrar, a grandes rasgos, cómo es el funcionamiento de estas modalidades de transporte.

Posteriormente, se expondrán las situaciones a las que se ven enfrentados los mencionados servicios. Así, se evidenciarán algunas dificultades en su prestación y las deficiencias de ambas modalidades. Lo anterior cobra relevancia dentro del presente escrito, ya que se busca demostrar que actualmente no existe, para el consumidor, ninguna otra alternativa eficiente capaz de cumplir con sus expectativas, por lo cual debería permitirse la operación de Uber en el país.

Por otra parte, se hará mención a Uber, específicamente a sus generalidades y características, la posición que ha manifestado el Estado colombiano frente a esta plataforma virtual y la posición de la empresa. Igualmente, se expondrán los motivos por los cuales se considera que la regulación actual es obsoleta, presenta grandes vacíos y no permite a nuevos actores o jugadores del mercado entrar a competir de una forma innovadora y creativa.

Por último, y en aras de definir una propuesta regulatoria, se hará un análisis económico con el fin de demostrar la deficiencia que presenta el mercado del servicio público individual de pasajeros en relación con un mercado de competencia perfecta y libre mercado.

\section{SERVICIO PÚBLICO DE TRANSPORTE TERRESTRE AUTOMOTOR INDIVIDUAL DE PASAJEROS EN VEHÍCULOS TAXI}

\section{A. Breve recuento histórico}

Es difícil establecer la fecha exacta en la cual se empezó a regular el servicio de transporte público en Colombia. Según Salazar (2001, pág. 202):

Aunque desde el inicio de la historia de la República ha sido intensa la expedición de normas del sector de transporte, la gran mayoría se restringieron, conforme con las circunstancias de la época, al diseño y la financiación de la infraestructura vial.

No obstante, tomaremos como punto de partida la Constitución Política de 1886, debido a que fue allí en donde se empezó a evidenciar una 
clara intervención del Estado en los servicios públicos, dentro de los cuales se encuentra el servicio de transporte. El artículo 32 de la mencionada disposición, si bien permitió la libertad de empresa y la iniciativa privada, le otorgó la facultad al Estado de intervenir en la economía con el fin de lograr un desarrollo integral.

Por su parte, el Código de Comercio de 1907 estableció el principio de regulación en el transporte público. Así, correspondía al Gobierno Nacional la inspección de las empresas públicas de transporte y el desarrollo de su respectiva reglamentación. A partir de esto, se expidió la Ley 15 de 1959 "Por la cual se da el mandato al Estado para intervenir en la Industria del transporte, se decreta el auxilio patronal del transporte, se crea el fondo de transporte urbano y se dictan otras disposiciones." Para el efectivo cumplimiento del mandato legal, el Gobierno emitió una serie de normativas, dentro de las cuales se pueden destacar la creación del Instituto Nacional del Transporte (INTRA) en 1968; el Decreto Ley 1393 de 1970 -Estatuto Nacional de Transporte-y el Decreto Ley 80 de 1987 que asignó funciones a los municipios en relación con el transporte.

Correlativamente a lo anterior, fue surgiendo una nueva modalidad en la prestación del servicio de transporte público. "La historia cita que la aparición de los primeros taxis en Bogotá fue totalmente accidental y fruto de una terrible crisis económica que sobrevino en 1930" (El Tiempo, 2008). Aunado a la crisis económica del país, en los años de 1925 y 1926 se produjo una gran sequía en el río Magdalena que obstaculi- zó el transporte fluvial de mercancías desde los puertos costeros hacia el interior. Debido a las circunstancias, una flota de 120 vehículos que trajo la empresa PRACO, representante e importadora de Ford para Colombia, quedó represada en el puerto de Barranquilla. Posteriormente, dichos vehículos fueron trasladados a la capital del país para su comercialización. Sin embargo, no existieron compradores y “Antonio María Pradilla, fundador de PRACO, decidió crear una flota de taxis para buscar alguna rentabilidad de los inventarios." (El Tiempo, 2008).

Poco tiempo después apareció la empresa Taxis Rojos cuyo propietario era el señor Leonidas Lara e Hijos, la cual aumentó el número de taxis en la ciudad de Bogotá. Así, gradualmente se fue incrementando el negocio de taxis en el país.

Una de las primeras normas relacionadas con el servicio de transporte individual de pasajeros mediante vehículos taxi que se expidió en Colombia fue el Decreto 826 de 1954, el cual definió lo que debía entenderse por Empresa de Transporte Automotor, y estableció una serie de requisitos mínimos para la prestación de este servicio (Rodríguez y Acevedo, 2012, págs. 262265).

Ahora bien, con la Constitución Política de 1991 se dio un cambio respecto al modelo de Estado. Así lo ha manifestado la Corte Constitucional, al afirmar:

La Constitución colombiana, al consagrar un Estado social de derecho en su artículo 1, combina el intervencionismo económico -lo cual 
supone una permanente posibilidad de restricción estatal de las libertades económicas con el radical respeto de los derechos civiles y políticos- por lo cual la restricción de estos últimos debe tener fundamento expreso y específico. En efecto, de un lado, la Constitución consagra una economía social de mercado dirigida, puesto que reconoce genéricamente que la iniciativa privada y la actividad económicas son libres (artículo 332) pero establece, también de manera global, que 'la dirección general de la economía estará a cargo del Estado' (artículo 333). (CConst, C-265/1994, A. Martínez).

Siguiendo esta línea argumentativa, el transporte público en Colombia ha sido considerado por la Constitución Política (CP), la ley y los entes estatales como un derecho, un servicio y una actividad económica. En este sentido, la Corte Constitucional se ha pronunciado en diferentes ocasiones, estableciendo que aquel es un servicio público de carácter esencial y de gran importancia para el desarrollo de algunos derechos fundamentales, tales como la libertad de movimiento y circulación (artículo $24 \mathrm{cP}$ ), el libre desarrollo de la personalidad (artículo $16 \mathrm{cP}$ ), y el derecho al trabajo (artículo 25 cP). Igualmente, se considera una actividad económica, ya que el transporte puede ser prestado directamente por el Estado o indirectamente a través de empresas privadas, produciendo un beneficio económico a quien lo presta.

\section{REGULACIÓN DEL SERVICIO PÚBLICO DE TRANSPORTE TERRESTRE AUTOMOTOR INDIVIDUAL DE PASAJEROS EN VEHÍCULOS TAXI}

\section{A. Ley 105 de 1993}

La Ley 105 de 1993 establece una serie de parámetros, los cuales sirven como guía para el desarrollo del servicio de transporte público en Colombia. El artículo $3^{\circ}$ define dicho servicio como:

Una industria encaminada a garantizar la movilización de personas o cosas por medio de vehículos apropiados a cada una de las infraestructuras del sector, en condiciones de libertad de acceso, calidad y seguridad de los usuarios sujeto a una contraprestación económica.

Al respecto, la ley en comento enuncia como principios fundamentales del servicio: (i) la soberanía del pueblo; (ii) la intervención del Estado, comprendida en la planeación, el control, la regulación y la vigilancia del transporte y de las actividades a él vinculadas; (iii) la libre circulación; (iv) la integración nacional e internacional; y (v) la seguridad, específicamente de los usuarios del servicio. Por otra parte, establece los principios específicos del servicio mencionado, como por ejemplo el acceso al transporte, el carácter de servicio público, la libertad de empresa y los permisos o contratos de concesión.

Igualmente, indica las características que reúne el acceso al transporte, donde el usuario goza de preferencia. En ese orden de ideas, se les 
otorga a los usuarios la facultad de elección del medio y modo del transporte; el que se les ofrezcan buenas condiciones de acceso, comodidad, calidad y seguridad; y el derecho a recibir información sobre dichos medios y modos ofrecidos, así como sobre sus formas de utilización. Correlativamente, se les impone a las autoridades competentes la obligación de diseñar y ejecutar políticas para el fomento del uso de los medios de transporte.

El carácter de servicio público de transporte implica que este se encuentra:

Bajo la regulación del Estado, quien ejercerá el control y la vigilancia necesarios para su adecuada prestación en condiciones de calidad, oportunidad y seguridad. (...). Existirá un servicio básico de Transporte accesible a todos los usuarios. Se permitirán de acuerdo con la regulación o normatividad el transporte de lujo, turísticos y especiales, que no compitan deslealmente con el sistema básico (num. 2, art. 3, L. 105/1993).

Teniendo en cuenta lo señalado en el numeral 6 , del artículo $3^{\circ}$ de la mencionada ley, para la constitución de empresas prestadoras de servicios de transporte solo se pueden exigir los requisitos establecidos en las normas y en los reglamentos sobre esta materia, en aras de proteger la libertad de empresa; y el Estado debe habilitar a estas empresas, formas asociativas de transporte y de economía solidaria, las cuales deben acreditar "capacidad técnica, operativa, financiera, de seguridad y procedencia del capital aportado". Así las cosas, solo se pueden imponer restricciones legales a la iniciativa pri- vada con el fin de evitar la competencia desleal, el abuso de la posición de dominio, asegurar la eficiencia y la seguridad del sistema.

Por último, para que una empresa pueda prestar el servicio se requiere de un permiso o de un contrato de concesión u operación, otorgado por la autoridad competente de acuerdo con el cumplimiento de las exigencias correspondientes (art. 7).

\section{B. Ley 336 de 1996}

Por su parte, la Ley 336 de 1996, "por la cual se adopta el Estatuto Nacional de Transporte" tiene como objetivos principales los siguientes: 1. La unificación de los principios y criterios que guiarían la regulación y la reglamentación de los diferentes tipos de transporte público en el territorio nacional; 2. Proteger la seguridad de los usuarios; y 3. Facultar al Estado en la regulación y vigilancia de dicha industria.

En esta ley el transporte adquiere el carácter de servicio público esencial, lo cual significa que primará el interés general sobre el particular, principalmente en lo relacionado con la garantía y la protección de los usuarios (art. 5); la actividad transportadora es definida como:

Un conjunto organizado de operaciones tendientes a ejecutar el traslado de personas 0 cosas, separada o conjuntamente, de un lugar a otro, utilizando uno o varios modos, de conformidad con las autorizaciones expedidas por las autoridades competentes basadas en los reglamentos del Gobierno Nacional (art. 6). 
Para que se pueda prestar el servicio de transporte público se debe cumplir con los criterios definidos en el capítulo 3 de la mencionada ley. Es así como dicho servicio, a nivel nacional, se puede prestar por empresas, personas naturales o jurídicas, siempre y cuando estén legalmente constituidas y debidamente habilitadas por la autoridad de transporte competente (art. 9); y en el artículo 10, define al operador o empresa de transporte como:

La persona natural o jurídica constituida como unidad de explotación económica permanente con los equipos, instalaciones y órganos de administración adecuados para efectuar el traslado de un lugar a otro de personas o cosas, o de unas y otras conjuntamente.

Como se indicó previamente, las empresas deben solicitar y obtener una habilitación para operar. Dicha habilitación, de acuerdo con la Ley 336 de 1996, es una autorización dada por la autoridad competente, de acuerdo con las condiciones fijadas por el Gobierno nacional (art. 11); es intransferible a cualquier título (art. 13); y es indefinida, siempre y cuando las condiciones originariamente exigidas relacionadas con el cumplimiento de los requisitos subsistan (art. 15).

Ahora bien, la fijación de las tarifas del servicio de transporte público, como se establece en el capítulo 7, corresponde al Gobierno nacional a través del Ministerio de Transporte, quien debe "formular la política y fijar los criterios a tener en cuenta para la directa, controlada o libre fijación de las tarifas en cada uno de los modos de transporte" (art. 29). Esto se realizará de acuerdo con los estudios de costos realizados por las autoridades competentes (art. 30).
La seguridad es un aspecto de vital importancia en la prestación del servicio mencionado, razón por la cual el capítulo 8 del mencionado Estatuto se encarga de ese tema. En primer lugar, se obliga al cumplimiento de diversas condiciones y especificaciones técnicas de los equipos destinados a la prestación del servicio de transporte público para efectos de la homologación (art. 31). En segundo lugar, se le impone a las empresas la obligación de "vigilar y constatar que los conductores de sus equipos cuenten con la licencia de conducción vigente y apropiada para el servicio, así como su afiliación al sistema de seguridad social según lo prevean las disposiciones legales vigentes sobre la materia" (art. 33). Igualmente, deben desarrollar programas de medicina preventiva para garantizar la idoneidad mental y física de los operadores de los equipos, y de capacitación para garantizar la eficiencia y tecnificación de los operarios (art. 35). Por otra parte, las empresas deben contratar a los conductores directamente, quienes son solidariamente responsables junto con el propietario del equipo (art. 36), y deben verificar que sus equipos reúnan las condiciones técnico mecánicas correspondientes (art. 38).

Así mismo, el Gobierno tiene la obligación de expedir reglamentos encaminados a "armonizar las relaciones equitativas entre los distintos elementos que intervienen en la contratación y prestación del servicio público de transporte, con criterios que impidan la competencia desleal y promuevan la racionalización del mercado de transporte" (art. 65). 


\section{Decreto 172 de 2001}

El objetivo principal de este decreto es:

Reglamentar la habilitación de las empresas de Transporte Público Terrestre Automotor Individual de Pasajeros en Vehículos Taxi y la prestación por parte de estas de un servicio eficiente, seguro, oportuno y económico, bajo los criterios básicos de cumplimiento de los principios rectores del transporte, como el de la libre competencia y el de la iniciativa privada, a los cuales solamente se aplicarán las restricciones establecidas por la ley y los Convenios Internacionales (art. 1).

Este se aplicará en todo el territorio nacional (art. 2), pero los alcaldes o las autoridades municipales competentes tienen la inspección, vigilancia y control de la prestación del servicio público mencionado (art. 9).

El artículo 6 define el servicio público de transporte terrestre automotor individual de pasajeros en vehículos taxi, de donde se desprende que: (i) se presta bajo la responsabilidad de una empresa de transporte; (ii) esta debe estar legalmente constituida y habilitada en esta modalidad; (iii) en forma individual; (iv) sin sujeción a rutas ni horarios; (v) el usuario fija el lugar de destino; y (vi) el recorrido lo establecen libremente las partes contratantes.

Al igual que en las leyes anteriores, a las empresas de vehículos taxi también se les exige la solicitud y la obtención de una habilitación para operar, la cual incluye la autorización para prestar el respectivo servicio únicamente en la modalidad solicitada (art. 10), la cual debe ser otorgada por la autoridad competente (art. 11). El capítulo 2 del título 2 establece las condiciones y requisitos que deben cumplir las personas jurídicas (art. 13) y las personas naturales (art. 14) para obtener dicha habilitación; el capítulo 3 regula el trámite a seguir; y el capítulo 4 indica la vigencia de aquella.

En concordancia con el principio de seguridad, se le impone a los prestadores del servicio la obligación de tomar pólizas de seguros, de responsabilidad civil contractual y extracontractual, que amparen a los usuarios, a los conductores o a terceros contra los riesgos inherentes a la actividad transportadora (art. 18). Cabe resaltar que la vigencia de los seguros será condición necesaria para la prestación del servicio (art. 20).

Con relación a la vinculación y desvinculación de los equipos se establece que las empresas habilitadas solo podrán operar con equipos registrados $\mathrm{y} / \mathrm{o}$ matriculados para dicho servicio (art. 26). Además, se define la vinculación de un vehículo a una empresa de transporte público como:

La incorporación de éste al parque automotor de dicha empresa. Se formaliza con la celebración del respectivo contrato entre el propietario del vehículo y la empresa, y se oficializa con la expedición de la tarjeta de operación por parte de la autoridad de transporte competente (art. 27).

Así mismo, se decreta la determinación de las necesidades de equipo y la asignación de matrículas. En consecuencia, las autoridades com- 
petentes deben supeditar la autorización o el ingreso de los taxis al servicio público por incremento, es decir, determinando si es necesario el ingreso del equipo mediante un estudio técnico (art. 35). El ingreso de estos vehículos, ya sea por incremento o por reposición, debe realizarse con vehículos nuevos (art. 36).

Para finalizar, el Decreto 172 de 2001 hace alusión a las tarjetas de operación. "La tarjeta de operación es el documento único que autoriza a un vehículo automotor para prestar el servicio público bajo la responsabilidad de una empresa de transporte, de acuerdo con el radio de acción autorizado" (art. 39), siempre y cuando cumpla con todos los requisitos correspondientes, y es otorgada por la autoridad de transporte competente (art. 40). Dicha tarjeta se expide por un año (art. 41), y los demás requisitos y características de esta se encuentran regulados en los artículos 42 y siguientes.

\section{CARACTERÍSTICAS DEL SERVICIO PÚBLICO DE TRANSPORTE TERRESTRE AUTOMOTOR INDIVIDUAL DE PASAJEROS EN VEHÍCULOS TAXI EN LA CIUDAD DE BOGOTÁ}

\section{A. Generalidades}

En Bogotá, una ciudad con 7,4 millones de habitantes en el 2010 (Departamento Administrativo Nacional de Estadística, 2005b), las autoridades no tienen la información básica referente a este sistema de transporte. Se estima que hay cerca de 675 taxis por cada 100.000 habitantes, es decir, 148 personas por cada taxi (Rodríguez y Acevedo, 2012, págs. 152-153).

De acuerdo con lo anterior, es importante resaltar que no existen estudios suficientes que revelen detalladamente las características específicas y particulares del servicio. Sin embargo, en el año 2005 la Dirección de Infraestructura y Transporte de la Contraloría de Bogotá presentó un informe en el cual el parque automotor matriculado en la ciudad de Bogotá ascendía a los 729.257 vehículos, de los cuales el 2,9\% correspondía al transporte público colectivo y masivo, el 6,3\% a transporte individual de pasajeros (taxis) con 45.790 vehículos aproximadamente, y el restante a vehículos particulares.

Por su parte, el reporte anual de la movilidad en Bogotá del año 2013 establece que "el servicio de transporte público individual se caracteriza por tener una flota prácticamente constante debido a la asignación de cupos para la operación del mismo. En el 2013 circularon por la ciudad 52.325 taxis" (Cámara de Comercio de Bogotá y Universidad de los Andes, 2014, pág. 44).

Actualmente, y basándonos en la información del Censo de Taxi del 19 de abril de 2015, realizado por la Secretaría Distrital de Movilidad, existen 51.543 taxis activos en la ciudad de Bogotá, y hay un número de 1.236 sin censar. De los taxis activos, 48.915 tienen la tarjeta de operación vigente, lo que significa que 2.628 taxis circulan sin esta tarjeta en la capital del país. 


\section{B. Cupos}

A través del Decreto Distrital 613 de 1993 se restringió el ingreso de vehículos clase taxi al servicio público individual de pasajeros, a excepción de que se haga una reposición del equipo. En otras palabras, solo se permite el ingreso de un vehículo taxi en la medida en que salga simultáneamente del servicio un vehículo viejo. La restricción mencionada se fundamentó principalmente en el gran número de taxis que circulaban en la ciudad, lo que ocasionaba altos índices de contaminación y accidentalidad, congestión y sobresaturación de equipo en la red vial, generando deficiencias en el servicio.

Siguiendo esta línea argumentativa, el Decreto Distrital 1029 de 2000 prorrogó la suspensión del ingreso por incremento de vehículos de servicio público tipo taxi en Bogotá hasta el 31 de diciembre de 2003. Por último, el Decreto Distrital 519 de 2003 prorrogó indefinidamente la mencionada suspensión, hasta tanto el organismo competente, mediante estudio técnico, determine la necesidad de incrementar el parque automotor.

En ese orden de ideas, fue la legislación misma la que se encargó de crear lo que hoy en día se conoce como "cupos" de los taxis. Según Ios autores Álvaro Rodríguez Valencia y Jorge Acevedo Bohórquez (2012), el cupo puede ser definido como "el derecho de reposición que tiene el propietario de un taxi en servicio cuando decida reemplazarlo por un vehículo nuevo. El cupo como tal no es un título o certificado" (pág. 38). Cabe resaltar que no fue directamen- te la ley la que le otorgó un valor a los cupos, sino el propietario de este, quien solo está dispuesto a cederlo a cambio de una contraprestación económica.

En términos generales, el fenómeno de los elevados valores de los cupos se explica porque se prohibió el ingreso de nuevos vehículos para la prestación de este servicio que constituye una actividad rentable en términos económicos. Sin embargo:

Ni el propietario del vehículo, ni el intermediario autorizado, pagan ninguna contribución al Estado por recibir la autorización para prestar este servicio de transporte público. Mientras las empresas afiliadoras cobran a los propietarios unas tarifas (de forma no regulada) y los propietarios obtienen millonarias utilidades por la valorización del cupo (rentas monopólicas), el servicio de taxis está produciendo cuantiosas externalidades negativas a la ciudad (Rodríguez y Acevedo, 2012, pág. 273).

Lo anterior se traduce en ganancias exorbitantes para los propietarios de los cupos, y en cero contribuciones al Estado por concepto de estos. Para el año 2004 el valor estimado de un cupo de taxi era de 18,4 millones de pesos y para el 2009 era de 46,4 millones de pesos (Rodríguez y Acevedo, 2012, pág. 443). Hoy en día, el valor de un cupo se encuentra alrededor de los 100 millones de pesos (Laserna, 2014).

Ahora bien, al momento de la expedición del Decreto 613 de 1993 se tenía un registro aproximado de 36.000 taxis en la ciudad de Bogotá, y en el 2015 es de 52.779 taxis. 
No se sabe mucho de la forma de funcionamiento de ese registro, pero sí que es un "consecutivo" (...) ¿Qué ha pasado entonces? ¿Cómo se explica esta contradicción? ¿Cómo es posible que, estando congelada la flota, se haya incrementado el límite máximo del consecutivo hasta el número 50.000? (Rodríguez y Acevedo, 2012, pág. 441).

Una de las posibles respuestas a estos interrogantes puede ser que:

El considerable valor del cupo ha generado incentivos muy fuertes para que el propio regulador (una entidad técnicamente débil y muy vulnerable a ser capturada por intereses espurios), vía procedimientos oscuros o non sanctos, haya permitido un aumento efectivo del número de taxis, a pesar del congelamiento legal. Puesto en cifras de fines de 2010, los 15.000 taxis adicionales que han ingresado "legalmente" al mercado en los últimos dieciocho años significan 15.000 cupos de 58 millones cop. Esta suma ha sido apropiada por quienes han participado en los tejemanejes conducentes al ingreso de tales vehículos al mercado, a lo largo de estos dieciocho años, una práctica que, en consecuencia, ha producido a sus perpetradores en promedio 48.000 millones cop por año. Todo lo anterior tiende a mostrar las graves distorsiones en la forma como se ha regulado el servicio en Bogotá (Rodríguez y Acevedo, 2012, págs. 445-446).

\section{Actores del mercado}

El servicio público de transporte en vehículos taxi en la ciudad de Bogotá se caracteriza por hacer confluir en un mismo mercado espacial y temporal a oferentes y demandantes del servi- cio. Así, los oferentes son todos aquellos encargados de prestar el servicio. Por su parte, los demandantes del servicio son todos los usuarios.

\section{Oferentes del servicio}

Los oferentes son aquellas personas encargadas de prestar el servicio, los cuales ejecutan el traslado de personas o cosas, de un lugar a otro, bajo la responsabilidad de una empresa de transporte legalmente constituida y debidamente habilitada en esta modalidad (art. 6, D.172/01).

Ahora bien, dentro de los oferentes del servicio existen diversos actores, como son los conductores, los propietarios de los vehículos y las empresas prestadoras del servicio. A continuación se hace una aproximación a cada uno de estos actores.

\subsection{Los conductores y propietarios}

Los conductores son uno de los actores principales dentro del servicio de transporte en vehículos taxi. Esto no solo porque en cabeza de ellos es que se desarrolla principalmente la prestación del servicio, sino además porque son los encargados de interactuar con los demás actores del mercado: los conductores no solo se relacionan con los demandantes del servicio, sino también con las empresas y con los propietarios de los vehículos. Adicionalmente, sobre los conductores recae una gran variedad de responsabilidades, que se ven manifestadas en la recaudación del dinero correspondiente a la tarifa que los usuarios pagan por el servicio, el 
mantenimiento del vehículo en condiciones de aseo y seguridad, el pago del arriendo correspondiente al propietario del vehículo, entre otras (Rodríguez y Acevedo, 2012, págs. 214-215).

"La industria de taxis es una fuente importante de empleo directo e indirecto en Bogotá. Se calcula que en la ciudad hay cerca de 59.000 conductores activos de taxi, para los cerca de 50.000 taxis registrados ante la autoridad" (Rodríguez y Acevedo, 2012, pág. 215). Sin embargo, es necesario resaltar que no todos los conductores son propietarios de los vehículos, por el contrario, la gran mayoría debe pagar al propietario un canon de arrendamiento por el uso del vehículo, además de un depósito.

\subsection{Empresas}

Como se indicó en párrafos anteriores, toda la normativa de transporte público exige el cumplimiento de unos requisitos y unas formalidades para que una persona natural o una empresa puedan prestar este servicio. En materia de taxis, el Decreto 172 de 2001, en su artículo 10, dispone que los interesados en prestar el servicio de transporte en vehículos taxi deben solicitar y obtener una habilitación para operar, y que dicha habilitación solo autoriza a la empresa para prestar el servicio en la modalidad solicitada.

Siguiendo la misma línea argumentativa, solo las empresas que sean habilitadas por la autoridad competente tienen la facultad de presar el servicio, por medio de los vehículos vinculados a la empresa, y que se encuentren debidamente registrados y matriculados. Cabe resaltar que la incorporación del vehículo al parque automotor de la empresa se oficializa mediante la emisión de la tarjeta de operación correspondiente.

A noviembre del 2009 existían en Bogotá 47 empresas habilitadas, que agrupaban los cerca de 50.000 taxis. (...) No existe regulación alguna sobre el precio que una empresa de transporte habilitada para la prestación del servicio público de taxis puede cobrar por la vinculación (afiliación) y por la cuota mensual o rodamiento. Las empresas tienen libertad para establecer el valor de los cobros mensuales (derecho de rodamiento) e iniciales de vinculación, siempre y cuando las condiciones estén claramente definidas en el contrato. (Rodríguez y Acevedo, 2012, pág. 267).

\section{Demandantes del servicio}

Los demandantes son todos los usuarios del servicio. Con base en lo expuesto previamente, los usuarios se relacionan directamente con los conductores, pues son estos quienes les prestan el servicio. De acuerdo con el artículo 6 del Decreto 172 de 2001, el usuario es quien fija el lugar de destino, pero el recorrido puede ser establecido libremente por las partes. Como contraprestación por este servicio, el usuario debe pagar el valor final indicado en el taxímetro.

Teniendo en cuenta que el transporte es un derecho, pues en él confluyen diferentes derechos fundamentales necesarios para el desarrollo y dignidad del individuo, el usuario goza de una gran variedad de facultades: puede exigir el cumplimiento del contrato de transporte, puede 
interponer quejas y reclamos, puede acudir a la Policía o a la entidad competente para la satisfacción de sus derechos, entre otros.

Sin embargo, el usuario también es sujeto de deberes como se establece en el artículo 55 de la Ley 769 de 2002. De dicha disposición se desprende que el pasajero, al igual que el conductor y el peatón, (i) debe comportarse de forma tal que no obstaculice, perjudique o ponga en riesgo a las demás personas; (ii) debe conocer y cumplir las normas y señales de tránsito que le sean aplicables; y (iii) debe obedecer las indicaciones de las autoridades de tránsito. Aunado a lo anterior, el principal deber del usuario es pagar la prestación correspondiente al servicio.

\section{SERVICIO PÚBLICO DE TRANSPORTE TERRESTRE AUTOMOTOR ESPECIAL}

El Servicio Público de Transporte Terrestre Automotor Especial se encontraba regulado por el Decreto 174 de 2001, sin embargo este fue derogado por el Decreto 348 de 2015. Es necesario resaltar que debido a la aparición de plataformas tecnológicas como Uber, que han roto con los paradigmas tradicionales en materia de transporte, las entidades estatales han expedido varias normas como el Decreto 348 de 2015, donde se imponen unas reglas más estrictas en materia de transporte especial.

Esta modalidad de servicio de transporte se define como:
Aquel que se presta bajo la responsabilidad de una empresa de transporte legalmente constituida y debidamente habilitada en esta modalidad, a un grupo específico de personas que tengan una característica común y homogénea en su origen y destino, como estudiantes, turistas, empleados, personas con discapacidad y/o movilidad reducida, pacientes no crónicos y particulares que requieren de un servicio expreso, siempre que hagan parte de un grupo determinable y de acuerdo con las condiciones y características que se definen en el presente decreto (D. 348/2015, art. 4).

En cuanto a las autoridades competentes, el Decreto 348 de 2015 señala que el Ministerio de Transporte será el encargado de regular toda la normativa y autorizar todo lo respectivo al servicio. Por su parte, a la Superintendencia de Puertos y Transportes le corresponde la inspección, vigilancia y control de este servicio especial. No obstante, las autoridades de tránsito deben realizar el control operativo de los vehículos, a través de su personal especializado.

Ahora bien, en materia de contratación se establecen unas reglas en el capítulo II del mencionado decreto. Por ejemplo, el artículo 12 dispone que dicha modalidad "solo podrá contratarse con empresas de transporte legalmente constituidas y debidamente habilitadas para esta modalidad". Aclara la norma que no se puede prestar el servicio sin un documento en el que conste el contrato de transporte entre la empresa habilitada y la persona natural o jurídica, donde se deben establecer las condiciones, obligaciones y deberes pactados por los contratantes. Se permite que las empresas hagan uso de medios 
tecnológicos o de firmas digitales para demostrar la existencia del contrato. Por último, la norma indica que las personas naturales o jurídicas no pueden contratar directamente el vehículo sin acudir a la empresa.

Dicho decreto también trae a colación diferentes tipos de contratos con base en las características de los usuarios. Así, existe contrato para transporte: (i) de estudiantes; (ii) de empleados; (iii) de turistas; (iv) un grupo particular de usuarios (particulares); y (v) de usuarios del servicio de salud.

Para poder prestar este servicio, las empresas deben estar legalmente constituidas además de solicitar y obtener una habilitación para operar en esta modalidad específica (artículo 17). En caso de que las empresas de servicio especial operen en una modalidad distinta a la cual corresponde su habilitación, incurrirán en la prohibición del artículo 44. Igualmente, se requiere de una tarjeta de operación, la cual:

Autoriza la operación de transporte que se realiza a través de un vehículo automotor, convirtiéndose en el permiso para operar en la modalidad de Servicio Público de Transporte Terrestre Automotor Especial, bajo la responsabilidad de una empresa debidamente habilitada, de acuerdo con los servicios contratados (art. 44).

En el artículo 95 se establece que la tarifa puede determinarse libremente entre las partes, pero siempre se debe reportar a las autoridades competentes:
Mediante el sistema de información que las entidades definan, el cual deberá almacenar la información de cada contrato celebrado, el valor por vehículo o recorrido, la clase de automotor, el número de sillas ofertadas, la tarifa por día, kilómetro de recorrido y la indicación de si se trata de servicio en ciudades o incluye tramos de carretera.

\section{PANORAMA ACTUAL}

En Bogotá, el problema del transporte se ve reflejado en el incumplimiento de los principios establecidos en las leyes anteriormente mencionadas. En ese sentido, es de gran relevancia destacar que uno de los principios más afectados es el de la preferencia que tiene el usuario para elegir el servicio. En otras palabras, el artículo 3 de la Ley 105 de 1993 faculta al usuario para la elección del medio y modo del transporte, el cual debe ser prestado en buenas condiciones de acceso, comodidad, calidad y seguridad.

Lo anterior se manifiesta en que a pesar del crecimiento territorial y poblacional de la ciudad de Bogotá, y de la preferencia de los habitantes por el uso del transporte público urbano, la calidad de este servicio es deficiente y no responde a las características mencionadas. La mayoría de los vehículos que prestan el servicio de taxi se encuentran en malas condiciones y no ofrecen todos los requisitos de seguridad necesarios. Por otra parte, es muy común que los conductores de los taxis se nieguen a llevar a una persona a un lugar determinado, y esto se traduce en una afectación directa al usuario del servicio. 
El problema de movilización de Bogotá no es un tema aislado ni de repercusiones limitadas dentro de la problemática de la ciudad, dado que el transporte es un problema que incide de manera directa sobre la calidad de vida de sus habitantes. Estudios sobre el grado de competitividad de la ciudad, han concluido que el tema del transporte junto con el de la inseguridad, son las dos principales debilidades estructurales de Bogotá (Contraloría de Bogotá, 2005, pág. 2).

En ese orden de ideas, la prestación del servicio de transporte por parte de vehículos taxis se ve enfrentada, actualmente, a una serie de retos, dentro de los cuales se encuentran las transformaciones en las necesidades y preferencias del consumidor. Por esta razón, algunas de las empresas prestadoras de esta modalidad de transporte se han venido ajustando a dichas preferencias y necesidades, ofreciendo sus servicios mediante plataformas tecnológicas que conectan a oferentes y demandantes. Un ejemplo de esto es la aplicación Taxis Libres.

Por su parte, Uber, evidenciando la falta de competencia efectiva en el sector, ha tratado de incursionar en esta modalidad de transporte para prestar un mejor servicio (incluso sin ser una empresa de transporte que haga parte de la modalidad de servicio individual). La base del negocio de estas empresas es satisfacer tanto a los usuarios como a sus necesidades, brindando un servicio con ingredientes adicionales, tales como la innovación, la facilidad de pago, la seguridad, entre otros, que lo hacen bastante atractivo para el público.
De esta forma llega Uber a Colombia, con la política empresarial de hacerle frente a una demanda insatisfecha en relación con el servicio de transporte individual de pasajeros en vehículos taxi. Seguidamente se procederá a explicar el funcionamiento básico de dicha plataforma.

\section{UBER}

Una Transport Network Company, como lo es la empresa internacional Uber Technologies Inc., ${ }^{3}$ es un medio para obtener servicios de transporte ofrecidos por terceros, en calidad de proveedores de transportes, conductores u operadores de vehículos. Dichos servicios se solicitan a través de la aplicación móvil "Uber" que se descarga desde un smartphone. ${ }^{4}$ Por esta razón, Uber ha sido catalogado como una plataforma virtual que conecta oferentes y demandantes del servicio de transporte.

Para poder acceder a la plataforma, los usuarios deberán descargar la aplicación móvil en sus dispositivos inteligentes. Una vez hecho esto, habrán de registrarse y facilitar a Uber su información personal, número de teléfono móvil y los datos de la tarjeta de crédito. Con estos datos se creará una cuenta con nombre y contraseña que le permitirá al usuario ingresar en cualquier momento.

3 "Transportation Network Companies (tncs) provide prearranged transportation services for compensation using an online-enabled application or platform (such as smart phone apps) to connect drivers using their personal vehicles with passengers." (U.S. California Public Utilities Comission, s. f.).

4 Teléfono móvil inteligente. 
Cuando el usuario requiere un servicio envía una solicitud que será recibida por el proveedor del transporte, quien podrá aceptarla o rechazarla. Cada dispositivo móvil dispone de un sistema de posicionamiento global (GPS, por sus siglas en inglés) que detecta la ubicación del solicitante del servicio, le envía la información al conductor y da un tiempo estimado de llegada. Una vez aceptado el servicio por parte del conductor, la aplicación le informa al usuario el nombre, número de matrícula del vehículo, teléfono y foto de la persona que lo recogerá.

El pago se realiza mediante la tarjeta de crédito registrada en la cuenta de Uber. Las tarifas son fijadas por Uber con base en criterios de oferta y demanda al momento de la solicitud del servicio. Así, de manera anticipada Uber le informa al usuario si existe o no una variación en la tarifa y será este quien decida aceptar o rechazar un mayor precio.

Al finalizar el servicio, Uber envía al correo electrónico del usuario una factura detallada que contiene: (i) tarifa base, (ii) distancia recorrida, (iii) tiempo, (iv) valor total, (v) imagen del recorrido, entre otros, y tanto al usuario como al conductor les da la opción de calificar el servicio a través de la aplicación en una escala de uno a cinco. Esta calificación es relevante para efectos de control de calidad y de seguridad.

\section{A. Uber en Colombia}

Uber llegó a Colombia en octubre del año 2013 y se constituyó legalmente como Uber Colombia S. A. S. El Certificado de Existencia y Representación Legal establece:
Objeto social: en desarrollo de lo previsto en el numeral 5 del artículo 5 de la Ley 1258 de 2008 , la sociedad podrá realizar cualquier actividad comercial o civil lícita, en Colombia o en el extranjero, incluyendo pero sin limitarse a la prestación de servicios por demanda de apoyo y soporte a personas naturales o jurídicas con dispositivos móviles o con aplicaciones basadas en desarrollos web, junto con todos los productos y servicios que resulten relacionados con este. [Cursivas añadidas].

Al igual que en las demás ciudades del mundo en las que opera, la aplicación móvil llegó a nuestro país para cubrir una demanda desatendida en el sector de transporte:

Un vocero de la compañía, que tiene su sede central en San Francisco (EE. UU.), indicó a El Tiempo: "La tecnología y la innovación han logrado resolver ineficiencias del sector y mejorado la calidad de vida de los colombianos al tener acceso a alternativas de movilidad más seguras y eficientes. Desconocer estos avances tecnológicos va en detrimento del interés y bienestar de los ciudadanos. (El Tiempo, 2014).

Vale la pena resaltar que Uber se concentra en un mercado relativamente pequeño, puesto que solo ha entrado a operar en las ciudades de Medellín, Cali, Barranquilla y Bogotá. Haciendo un cálculo aproximado, el número de habitantes de estas cuatro ciudades es de 13.500.000. Teniendo en cuenta que, de acuerdo con los voceros de Uber para Colombia, la aplicación cuenta con un número de 100.000 usuarios en el país, los demandantes del servicio representan únicamente un 0,7\% del total de esta población. 
Igualmente, la plataforma se concentra en un sector de la población muy específico, pues los usuarios del servicio presentan las siguientes características:

1. Ser titular o tener acceso a una tarjeta de crédito:

Según cifras de asobancaria (2015), el indicador de bancarización en Colombia es del $72,5 \%$. Sin embargo, solo 6.8 millones de personas en el país cuentan con una tarjeta de crédito, lo cual es una cifra muy baja en relación con el número total de habitantes del país.

\section{Tener un smartphone:}

Según un informe de penetración de 'smartphones' en América Latina entre 2013 y 2018 de eMarketer, una compañía especializada en estudios de mercado, Colombia se ubicó como el tercer país de la región en cantidad de usuarios en teléfonos inteligentes en 2014, con 14,4 millones (El Tiempo, 2015).

Considerando que Uber cuenta con 100.000 usuarios, el porcentaje de los demandantes que potencialmente puedan usar la aplicación a través de sus teléfonos inteligentes corresponde únicamente al 0,69\% de la población total de colombianos con smartphone.

3. Contar con plan de datos o conexión permanente a Internet:

Según el informe del cuarto trimestre del año 2014 del Ministerio de Tecnologías de la Información y las Comunicaciones (MinTic), en Co- lombia el número total de personas con acceso móvil a Internet (sean suscriptoras o abonadas) es de 26.978.219. De modo que considerando que el número de usuarios de la plataforma Uber es de 100.000 personas, estas representan únicamente el 0,37\% del total de quienes cuentan con acceso a Internet móvil.

De acuerdo con el panorama anteriormente descrito, y partiendo de la base de que en Colombia no existe hasta el momento una modalidad de transporte individual que se pueda considerar como taxis de lujo, el funcionamiento de Uber en el país ha generado controversia debido a su forma de operación. Al no contar con ninguna otra opción para asegurarle a los usuarios la especialización de su demanda, la plataforma ha operado poniendo en contacto a los 100.000 usuarios del país con unos conductores que están afiliados a empresas que aunque se encuentran legalmente constituidas como prestadoras de Servicio Público de Transporte Terrestre Automotor Especial, están prestando el servicio de Transporte Público Terrestre Individual.

¿Por qué Uber entró a operar directamente con los prestadores del Servicio Público de Transporte Terrestre Automotor Especial?

En vista de que el usuario de Uber es más exigente, y requiere la prestación de un servicio con calidad, seguridad y eficiencia que no es ofrecido por las empresas de Servicio Público de Transporte Terrestre Individual, la plataforma encontró en el servicio especial una modalidad de transporte más competitiva y que respondía a las necesidades de un segmento de la po- 
blación que se encontraba hasta el momento desatendido. A simple vista, las características del parque automotor de las empresas de transporte especial son mucho mejores que las del transporte individual; los demás valores agregados los añade Uber.

Lo anterior ha generado dos posiciones contrarias y polémicas las cuales procedemos a explicar.

\section{B. Posición del Estado}

El Estado, por intermedio del Ministerio de Transporte, la Superintendencia de Puertos y Transportes y la Secretaría Distrital de Movilidad ha manifestado, a través de diferentes medios, que la prestación del servicio de transporte individual de pasajeros con vehículos de servicio público especial no es legal, y que las plataformas tecnológicas que lo faciliten tampoco se "ajustan a derecho". Estas entidades fundamentan su posición, principalmente, en que según la ley los vehículos solo pueden prestar el servicio bajo la modalidad para la cual fueron habilitados.

En primer lugar, la Superintendencia de Puertos y Transportes emitió el 9 de julio de 2014 la Circular Externa n. ${ }^{\circ} 00000013$, donde indica que el Servicio Público en modalidad Especial debe ajustarse a lo estipulado en el artículo 6 del Decreto 174 de 2001, y que no se podrá asemejar al Servicio Público de Transporte Terrestre Automotor Individual de Pasajeros en Vehículos Taxi:

En este orden de ideas el omitir o no dar cumplimiento a la normatividad antes anotada, dará lugar a las investigaciones administrativas correspondientes y la imposición de las eventuales sanciones a las empresas que permitan y/o prohíben esta clase de prácticas, además de las sanciones a que se verían abocados por parte de las autoridades de tránsito que actuando dentro de la órbita legítima de sus funciones legales, podrá realizar los operativos que considere conducentes y pertinentes con miras a imponer las sanciones a que haya lugar por la prestación de un servicio no autorizado.

Siguiendo la misma línea, el 30 de diciembre del año 2014 esta misma Superintendencia emitió la Circular Externa número 00000024 , dirigida a las autoridades de tránsito y transporte municipal, distrital y metropolitano, donde solicita a dichas autoridades aplicar, dentro de sus competencias, las medidas tendientes a la inmovilización de vehículos de servicio particular y público en las modalidades de pasajeros por carretera y especial que transgredan lo previsto en los decretos 171, 172 y 174 de 2001 y demás disposiciones concordantes.

A su vez, la circular hace referencia expresa a la aplicación Uber, y establece que se deben:

Aplicar las medidas tendientes a la inmovilización de vehículos de servicio particular y público que presten servicio no autorizado a través de la plataforma "UBER", incumpliendo lo previsto en la circular No. 013 del 9 de julio de 2014, emitida y publicada en la página Web de esta entidad.

En febrero de 2015 se expidió el Decreto 348 del mismo año, que derogó expresamente el Decreto 174 de 2001, el cual regulaba hasta la 
fecha el Servicio Público de Transporte Terrestre Automotor Especial.

La ministra de Transporte, Natalia Abello, en repetidas ocasiones ha sido clara en su posición sobre la ilegalidad de Uber. Fundamenta su argumento en que si bien Uber es una plataforma tecnológica, no está constituida como una empresa prestadora del servicio de transporte, y al prestar dicho servicio está infringiendo la ley. Igualmente, considera que "la intermediación de las aplicaciones móviles entre clientes y conductores de transporte especial es una actividad no regulada y, por lo tanto, ilegal" (El Tiempo, 2015). Por otra parte, afirma que los vehículos que se encuentran prestando el servicio a través de Uber están habilitados para la modalidad de transporte especial, lo que no contempla el servicio de transporte individual de pasajeros.

Hace algún tiempo, en las redes sociales se hizo público un video en el que tanto la ministra de Transporte como el ministro de Trabajo (Luis Eduardo Garzón) conversan con el vocero de los taxistas en Bogotá, Hugo Ospina. En este los dos funcionarios declararon que Uber no sería legalizado, y que serían los taxistas quienes tendrían la posibilidad de acceder al negocio de los taxis de lujo, mediante reposición del vehículo.

Teniendo en cuenta lo anterior, la Superintendencia de Puertos y Transportes emitió un comunicado el 6 de marzo de 2015, en el que informa que está investigando a 23 empresas de transporte especial y a los propietarios de vehículos que utilizan plataformas tecnológicas violando las normas de transporte individual y especial.

En conclusión, la posición del Estado se manifiesta en la expedición de circulares, normas y comunicados en los que se declara la ilegalidad de la plataforma virtual Uber, y en los cuales no se busca incluir o proponer una alternativa integradora, sino por el contrario una excluyente.

\section{Posición de Uber}

Uber, a través de diferentes voceros, dentro de Ios cuales se encuentra Ana Paula Blanco, ha hecho saber que:

Es una firma legalmente constituida que paga sus impuestos y que sus 'socios conductores' están legalmente afiliados a empresas reconocidas por el Ministerio de Transporte. Es decir, todos los componentes del servicio de Uber plataforma, conductores, automóviles y servicio- cumplen con la ley. 'Lo que ofrecemos es una intermediación'. (Semana, 2014).

En referencia a las declaraciones de la ministra, han manifestado que la posición de la funcionaria desconoce los derechos de los 100.000 consumidores, uno de ellos el de elegir libremente el servicio de transporte que mejor se acomode a sus necesidades y preferencias. Por consiguiente, los ciudadanos "serían privados de una alternativa que han elegido para moverse en forma segura y confiable." (El Tiempo, 2015).

Actualmente, Uber se encuentra buscando un acercamiento con el Gobierno nacional, específicamente con el Ministerio de Transporte, con 
el fin de hacer parte de los diálogos y conversaciones frente a la nueva regulación del servicio de lujo:

Los representantes de la plataforma expresaron que su interés es formar parte de las conversaciones que se están llevando a cabo alrededor de la nueva regulación. 'Queremos que se ponga a los ciudadanos en primer lugar, cuidando su seguridad, incentivando la inversión y la innovación y mejorando las opciones', afirmaron. (El Tiempo, 2015).

Lo anterior, para que se tengan en cuenta no solo su posición y sus derechos, sino también los de los consumidores y conductores, ya que los únicos intereses que se han visto cobijados en los pronunciamientos del Gobierno son los de los taxistas.

Por otra parte, los usuarios del servicio también han participado en diversas manifestaciones en contra del Ministerio de Transporte y las demás entidades que han catalogado a Uber de ilegal. Prueba de ello es el derecho de petición respaldado por más de 26.000 firmas de usuarios, radicado en el mencionado Ministerio solicitando la regulación del servicio y, además, que se incluya a la ciudadanía y a los demás actores interesados que se están dejando de lado (Redacción de El País, 2015).

Igualmente, se han visto iniciativas impulsadas por diferentes ciudadanos a través de las redes sociales, dentro de las cuales cobra gran relevancia la convocatoria al día de no taxi. Con esto, los usuarios manifiestan la necesidad de responder a las constantes amenazas del gremio de taxistas con un paro. Así, lo manifestó el "post" que impulsó esta iniciativa en las redes sociales:

Y ya tendrán los reyes del volante sus argumentos para quejarse $y$, sobre todo, amenazar y someter a la ciudad, como siempre lo hacen, pero los usuarios habituales de taxi cada día nos llenamos de argumentos también, ya bien conocidos, pero al parecer desestimados por las autoridades. (El Espectador, 2015).

\section{La deficiente y obsoleta regulación del servicio}

Es innegable que hoy en día cualquier estudio que verse sobre crecimiento económico y desarrollo de los países arrojará, dentro de sus resultados, que una de las variables más importantes o representativas para lograr este objetivo es la innovación y el progreso técnico. Desde hace mucho tiempo se demostró que el crecimiento económico de los Estados se debe, en gran medida, a la investigación y el desarrollo tecnológico.

Colombia, a pesar de contar con políticas fuertes para el fomento de la investigación y el desarrollo, tiene un sistema de innovación bastante pequeño, puesto que su gasto en I+D es solo del $0,2 \%$ del PIB. Por ello, en reiteradas ocasiones se ha insistido en la necesidad de fomentar la innovación, la investigación y el desarrollo, y en conminar esfuerzos para posicionar a Colombia como una economía sostenible que estimule factores como la eficiencia y la productividad.

La historia económica de Colombia y los signos emergentes de su futuro apuntan a la impor- 
tancia de impulsar la innovación para aumentar la productividad, no sólo en manufactura y la agricultura, sino también en los servicios, un área en la que el progreso de Colombia ha sido débil. Tanto las infraestructuras, especialmente las de una avanzada tecnología de información y comunicación (TIC), como los servicios de transporte tienen una profunda influencia en la competitividad de otros sectores económicos. La innovación ofrece posibilidades para ingresar nuevas actividades como parte de un proceso acumulativo de diversificación económica. Las nuevas actividades, impregnadas cada vez con más habilidades, capital y conocimiento, contribuirán al incremento de la productividad al aumentar la eficiencia de las actividades existentes. (Organización para la Cooperación y Desarrollo Económicos, 2014, pág. 6). [Cursivas añadidas].

Aunque lo dicho anteriormente aplica para todos y cada uno de los sectores de la economía, consideramos que para el caso bajo estudio es necesario tener en cuenta únicamente la influencia de la tecnología y la innovación en el desarrollo del sector de transporte individual de pasajeros en Colombia. Si bien las normas de transporte público individual en nuestro país, a primera vista parecen cumplir con los principios del transporte y los derechos constitucionales consagrados como pilares fundamentales de dicho servicio, su aplicación se ha vuelto ineficiente y obsoleta en la práctica, entre otras cosas, debido a la ausencia de herramientas tecnológicas y de innovación.

Así lo señalan Rodríguez y Acevedo (2012, pág. 135):
Pese a que los principios de transporte establecen algunos con los que se propende hacia sistemas de transporte seguros y eficientes, donde el interés general prima sobre el particular, el resultado pragmático de las normas revisadas ha sido en buena medida contrario a dichos principios.

Ahora bien, el problema de la regulación de Colombia en esta materia no es necesariamente:

La existencia (o carencia) de más o mejores normas, aunque ciertamente es mucho lo que se puede y se debe mejorar en este aspecto; es algo más estructural e institucional, y está en la extrema debilidad técnica y conceptual de la autoridad reguladora nacional (ministerio), y de las autoridades locales (secretarías de tránsito). (Rodríguez y Acevedo, 2012, pág. 139).

Con base en lo anterior, consideramos que ya es hora de que el Ministerio de Transporte y el MinTic trabajen en conjunto y de manera coordinada para darle cabida a la tecnología y a la innovación en el sector del transporte. Es necesario que los entes reguladores entiendan varios puntos antes de declarar como "ilegal" a una plataforma tecnológica que, en últimas, no ha encontrado un marco normativo o regulatorio al cual ajustarse en nuestro país. Lo anterior, debido a que, como hemos sostenido a lo largo de este escrito, Uber no es una empresa prestadora de servicios de transporte, y por lo tanto no se encuentra habilitada para prestar dichos servicios. Al momento de desarrollar el presente escrito, el uso de plataformas tecnológicas como intermediarias en el servicio de transporte de lujo individual de pasajeros en Colombia 
no se encontraba regulado. En esta medida, y siguiendo el principio liberal de legalidad, "todo aquello que no esté expresamente prohibido por la ley, está permitido."

Es necesario que tanto el Ministerio de Transporte como el MinTic entiendan que nos encontramos en un mundo globalizado y cada vez más inmerso en la economía digital, en donde nace lo que se conoce como Multi-Sided Platforms. ${ }^{5}$ Las organizaciones o modelos de negocio tienden a crear valor permitiendo la interacción entre diferentes segmentos del mercado, reduciendo los costos de transacción. Uber ha sido definida como una de estas plataformas. ${ }^{6}$ Su página web la presenta como una sociedad que "ofrece información y un medio de obtener servicios de transporte ofrecidos por terceros que son proveedores de transporte, conductores u operadores de vehículos" [cursivas fuera del original]. Es así como a través de esta aplicación se crea valor cuando Uber actúa como intermediario entre quienes solicitan un servicio de transporte y quienes ofrecen dicho servicio.

$5 \quad$ "Many diverse industries are populated by businesses that operate "two-sided platforms." These businesses serve distinct groups of customers who need each other in some way, and the core business of the two-sided platform is to provide a common (real or virtual) meeting place and to facilitate interactions between members of the two distinct customer groups. Platforms play an important role throughout the economy by minimizing transactions costs between entities that can benefit from getting together. In these businesses, pricing and other strategies are strongly affected by the indirect network effects between the two sides of the platform." (Evans, 2011, pág. 2).

$6 \quad$ "Uber is a multi-sided platform for ride-sharing. Potential passengers connect with taxi drivers using a smartphone app where gps location sharing, pickup timing (typically within 8 minutes of request), and payment are all executed online. No money exchanges hands." (A former Student, 2014, pág. 1)

\section{E. ¿Competencia desleal?}

Diferentes personas, especialmente los taxistas, han catalogado a Uber como una empresa que compite deslealmente con los taxis, por la supuesta conducta de violación de normas.

La Ley 256 de 1996 tiene como fin garantizar los derechos de todos los participantes del mercado, prohibiendo aquellos actos o conductas que se consideran desleales. El artículo 2 define como desleal las conductas que se realizan dentro del mercado y que tengan fines concurrenciales. Igualmente, dispone que "la finalidad concurrencial del acto se presume cuando este, por las circunstancias en que se realiza, se revela objetivamente idóneo para mantener o incrementar la participación en el mercado de quien lo realiza o de un tercero."

Para que se pueda aplicar esta norma se debe cumplir con el elemento objetivo anteriormente mencionado; con el subjetivo, que hace referencia a comerciantes o a cualquier participante del mercado; y con el elemento territorial, que implica que los efectos principales de la conducta se den o se vayan a dar en el mercado colombiano.

Ahora bien, la conducta desleal por violación de normas se encuentra establecida en el artículo 18 de la mencionada ley, de donde se deprende que:

La configuración de la conducta desleal en comento reclama la concurrencia de los siguientes elementos: (i) la infracción de una norma diferente a las contempladas en la Ley 256 de 1996; (ii) la efectiva realización en el mercado 
de una ventaja competitiva como consecuencia de la anotada vulneración, y (iii) que esta resulte significativa. (Superintendencia de Industria y Comercio, sentencia 4230 de 2012, A. León).

Por último, vale la pena recalcar que además de mencionar la ley que se considera infringida, es necesario probar que tal vulneración existió efectivamente y que generó un beneficio para el competidor.

Tal y como lo establece el doctor Víctor Ayalde Lemos (2015), es claro que uno es el mercado de las plataformas tecnológicas y otro el de los servicios de transporte que se asocian a estas. De esta forma, Uber, como plataforma tecnológica, no compite deslealmente con los taxis debido a que funciona como un simple intermediario entre oferentes y demandantes del servicio de transporte, mientras que los taxis funcionan como empresas que prestan directamente el servicio.

Conviene resaltar, como se mencionó anteriormente, que existe un vacío normativo frente a los servicios que presta Uber. Por lo tanto, al no encontrarse regulado el tema de la intermediación en la prestación del servicio de taxis de lujo, no habría ninguna infracción en los términos de la Ley 256 de 1996.

Con respecto al servicio de transporte que se asocia a Uber, si bien puede llegar a considerarse que existe una infracción de normas (Decreto 348 de 2015), dicha infracción no le permite a Uber adquirir una ventaja competitiva frente a sus potenciales competidores (empresas de servicio público de transporte terrestre individual) que sea significativa en términos de mercado, puesto que como se evidenció anteriormente, Uber solamente cuenta con un número de 100.000 usuarios en las ciudades de Barranquilla, Cali, Medellín y Bogotá, que corresponden al $0,7 \%$ de la población total de dichas ciudades.

Estos y muchos otros aspectos son los que deben plantearse las autoridades nacionales antes de tildar de ilegal a una empresa que rompe con los esquemas tradicionales en la prestación del servicio. Si lo que existe es un vacío normativo, se deberá pensar en la forma más racional de regularlo (si es que debe estar regulado), y si por el contrario, se establece que efectivamente la plataforma tecnológica no se ajusta a la normatividad vigente, las autoridades deberán atender las súplicas de los consumidores de este servicio, haciendo prevalecer su derecho a la libertad de elección, y encontrar la forma en que dicha plataforma pueda ajustarse a la normatividad del país.

\section{ANÁLISIS ECONÓMICO}

Uno de los resultados más relevantes que ha tenido la economía es que los mercados competitivos $^{7}$ de largo plazo tienen la propiedad de asignar los recursos de forma eficiente. Así pues,

Para alcanzar la asignación eficiente de recursos en el sentido de Pareto es necesario que

"Un mercado perfectamente competitivo es aquel en el cual todos los participantes son precio-aceptantes." (Krugman y Wells, 2006, pág. 207). 
(...) la tasa de intercambio entre dos bienes (...) sea igual para todos los agentes económicos. En una economía en competencia perfecta, la relación del precio de $x$ con el de $y$ da por resultado esta tasa común de intercambio a la que se ceñirán todos los agentes. (Nicholson, 2007, pág. 364).

Adicionalmente, los precios son un elemento fijo en la toma de decisiones de los consumidores y de las empresas, ya que mediante estos se maximizan sus utilidades, lo que genera que las tasas de intercambio entre dos bienes sean iguales a las de los mismos bienes en el mercado. Como consecuencia, todos los agentes enfrentan los mismos precios, las tasas de intercambio se igualan y se logra una asignación eficiente.

Pero para que esto suceda se tienen que cumplir los siguientes supuestos:

1. Inexistencia de barreras de entrada o salida. Las barreras de entrada o de salida, como su nombre lo indica, son obstáculos que se le imponen a una empresa para poder entrar o salir del mercado.

2. Homogeneidad del producto o servicio. "Un bien es un producto homogéneo cuando los consumidores consideran que los productos de los diferentes productores son el mismo bien." (Krugman y Wells, 2006, pag. 208).

3. Coexistencia de muchos ofertantes y demandantes que están dispuestos a vender o comprar.
4. Los vendedores y compradores no ejercen influencia en el precio, porque ninguna empresa o comprador es lo suficientemente grande para hacerlo. Por tanto, es fijado de manera impersonal por el mercado.

5. Información perfecta. Cuando todos los agentes del mercado tienen conocimiento de los precios.

Cuando se cumplen los supuestos anteriormente mencionados se puede decir que dentro de la estructura de mercado correspondiente no se produce una pérdida irrecuperable de eficiencia.

\section{A. Deficiencia de los taxis frente al mercado de competencia perfecta}

Ahora bien, en el caso específico de los taxis no se cumplen todos los supuestos para que exista una competencia perfecta, y consecuentemente una eficiencia económica.

En primer lugar, se puede afirmar que sí existen grandes barreras de entrada para que otras personas o empresas ingresen a competir en el mercado del servicio individual de pasajeros. Como se indicó en párrafos previos, mediante el Decreto Distrital 613 de 1993 se limitó la entrada de vehículos clase taxi para la prestación del servicio de transporte individual. Únicamente se puede ingresar un vehículo cuando se hace la reposición, es decir, cuando sale simultáneamente del servicio un equipo viejo. Esto condujo a varias consecuencias negativas en el mercado del servicio, como se mostrará a continuación. Con la restricción del ingreso de taxis disminuye 
el número total de viajes que se pueden efectuar, se genera una presión para que el precio de equilibrio ${ }^{8}$ aumente, lo que conlleva que exista una diferencia entre el precio de la demanda

Gráfica 1. Competencia perfecta vs. asignación de cuotas de mercado

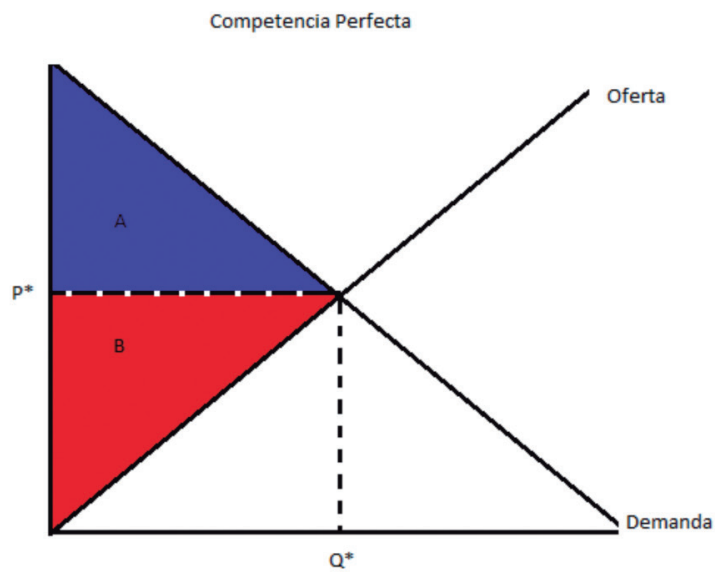

Fuente: elaboración propia.

En el segmento izquierdo de la gráfica se puede observar un mercado en competencia perfecta. El área que se encuentra por encima de la curva de la oferta hasta el precio de equilibrio es el excedente del productor, mientras que el área por debajo de la curva de demanda hasta el precio de equilibrio es el excedente del consumidor. El excedente total corresponde a las áreas azul y roja, es decir, está representado por los triángulos A y B. Como se desprende de la gráfica, el precio de equilibrio está dado por $\mathrm{P} *$ y las cantidades de equilibro por Q*. En esta intersección ni demandantes ni oferentes tienen incentivos para cambiar sus decisiones de producción y consumo.

8 "Un precio de equilibrio es aquel donde la cantidad demandada es igual a la cantidad ofrecida. A este precio, ni los demandantes ni los oferentes tienen incentivo alguno para modificar sus decisiones económicas." (Nicholson, 2007, pág. 288). y el de la oferta, produciendo una pérdida irrecuperable de eficiencia, como se muestra en la gráfica 1:

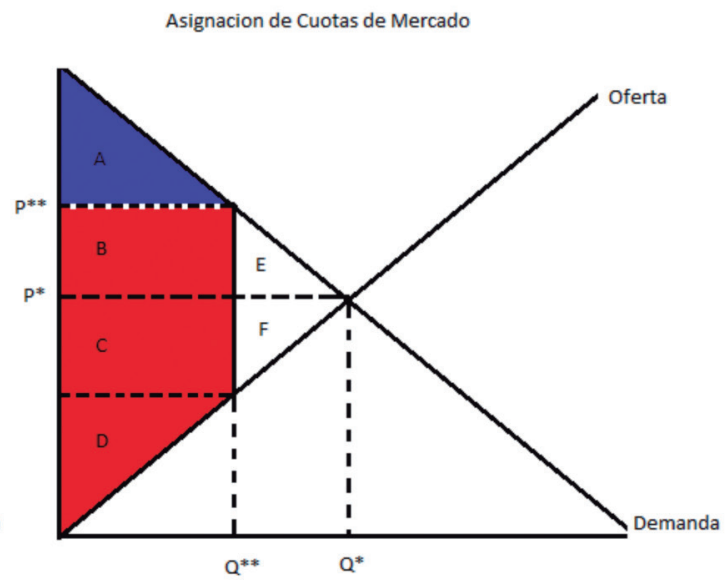

Por el contrario, en el segmento derecho de la gráfica se imponen cuotas de mercado, las cuales se expresan como el paso de $Q^{*}$ y $Q * *$. Debido al movimiento de la oferta a lo largo de la curva, el nuevo precio de equilibrio pasa de $\mathrm{P}$ * a $\mathrm{P} * *$. El excedente del consumidor está dado por el área debajo de la curva de demanda hasta el precio de equilibrio, representado por el triángulo A. En contraposición a lo que ocurre en un mercado en competencia perfecta, donde el excedente del consumidor correspondía a A, $B$ y $E$, en un mercado con cuotas se reduce solo al triángulo A. Por su parte, el excedente del productor está determinado por el área debajo de la curva de oferta hasta el precio de equilibrio, representado por B, C y D. En un mercado competitivo el excedente del productor estaba dado por C, D y F. Sin embargo, es necesario aclarar 
que en este caso no se sabe si el excedente del productor es mayor en un mercado competitivo que en uno con cuotas, ya que depende de las formas de las curvas de oferta y demanda. Pero lo que sí está claro es que existe una transferencia del excedente de los consumidores a los productores, representado por el área B. Por último, se puede afirmar que existe una pérdida de eficiencia plasmada en los triángulos $\mathrm{E}$ y $\mathrm{F}$, reduciendo así el bienestar general.

Un segundo motivo por el cual creemos que los taxis no cumplen con los supuestos para que exista un mercado en competencia perfecta y económicamente eficiente, es porque el precio no es fijado por el mercado, pues es el Estado el que se ha encargado de establecer las tarifas que estos pueden cobrar. Dicha intervención estatal tiene como sustento (i) impedir que se aumenten los precios dada la disminución de la oferta, y (ii) compensar el efecto negativo en el bienestar del consumidor. Sin embargo, esta regulación de tarifas no corrige la pérdida de eficiencia producida por la asignación de las cuotas de mercado, en este caso los cupos.

Incluso, la regulación de tarifas genera un efecto contraproducente sobre el bienestar social, debido a que la gran mayoría de las veces los conductores de los taxis no son los verdaderos dueños de los carros, y a que estos deben pagar una contraprestación diaria al propietario. La imposibilidad de un aumento en las tarifas ha llevado a que los conductores de los taxis, en su afán por reducir costos y obtener ganancias razonables, hayan tenido que deteriorar la calidad del servicio que prestan, en detrimento de los consumidores.
Por otra parte, teniendo en cuenta las grandes barreras de entrada para poder prestar el servicio de taxi y las altas rentas que genera el negocio, algunas empresas y particulares han buscado la forma de apropiarse de los "cupos" creados mediante el Decreto 613 de 1993, expedido por el Alcalde Mayor de Bogotá, D. C. Como consecuencia de lo anterior, el mercado de taxis en Bogotá y en otras ciudades del país tiene una estructura oligopólica, donde pocos oferentes tienen poder para establecer los precios de mercado. ${ }^{9}$

\section{B. Uber en el mercado}

Teniendo en cuenta lo expuesto previamente, es decir, que el mercado de los taxis funciona bajo una estructura oligopólica donde pocos oferentes controlan el mercado de los cupos generando un deterioro del servicio de transporte individual en la ciudad, surgen nuevas alternativas de movilidad. Así, los carros blancos que conecta Uber con los demandantes del servicio de transporte se convierten en una opción atractiva para los consumidores, en la medida en que logran obtener un servicio con mayores estándares de calidad casi por el mismo precio.

Aunado a lo anterior, podemos ver que Uber cumple en mayor proporción las condiciones de un mercado de competencia perfecta, basándose en el mismo funcionamiento de la aplicación.

\footnotetext{
9 "Los economistas denominan competencia imperfecta a aquella situación en la que aunque las empresas compiten, también poseen cierto poder de mercado, lo que les permite influir en los precios de mercado (...) existen dos importantes formas de competencia imperfecta: el oligopolio y la competencia monopolística." (Krugman, Wells y Olney, 2008, pág. 302).
} 
1. No hay barreras de entrada. A diferencia de los taxis, la persona que cumpla con una serie de requisitos que exige la aplicación está en capacidad de inscribir su carro en la plataforma.

2. Homogeneidad del producto e información perfecta. Aunque no todos los carros y conductores inscritos a Uber son iguales, la plataforma garantiza unos estándares básicos de calidad. Además, se le permite al consumidor acceder a información del servicio que está adquiriendo, como la foto y calificación del conductor, el modelo del carro, la ubicación, la tarifa detallada y la certeza de que el conductor se ha sometido a una previa investigación, lo que no ocurre con los taxis, ya que la mayoría de las veces no se conoce de manera detallada esta información, lo que puede generar fallas de mercado por asimetrías de información; esto se conoce como problemas de selección adversa.

3. Los vendedores y compradores no ejercen influencia en el precio de mercado, puesto que este es fijado de manera impersonal por el mercado. En el caso de Uber los precios se determinan por medio de oferta y demanda, lo que genera una asignación eficiente de los viajes, mientras que para el caso de los taxis el precio está regulado por los taxímetros, lo que genera deficiencias económicas.

\section{PROPUESTA Y CONCLUSIONES}

Teniendo en cuenta toda la información expuesta hasta el momento, se puede afirmar que: (i) la legislación actual es obsoleta; (ii) el servicio de transporte en las modalidades descritas presenta grandes deficiencias y los usuarios han buscado alternativas de movilidad diferentes; (iii) la tecnología ha tenido un gran efecto en todos los sectores económicos, y cobra gran relevancia en materia de transporte; y (iv) los avances tecnológicos, en el caso concreto de Uber, han generado polémica y grandes debates, de donde se derivan posiciones polarizadas.

Consideramos que en el caso bajo estudio se presenta una grave afectación a los principios del derecho de la competencia. El derecho de la competencia puede definirse como aquel conjunto de disposiciones que se ocupan de proteger los intereses de los consumidores a través de la libre competencia en los mercados. La libre competencia en los mercados se ha protegido desde hace algún tiempo, puesto que se considera de trascendental importancia para el desarrollo económico y social de un país. En la actualidad la mayoría de los países del mundo han desarrollado la cultura de la competencia en los mercados, y en consecuencia han expedido, piensan expedir o están en trance de modificar su normativa de libre competencia, con el fin de garantizar el funcionamiento agonal del mercado, de tal manera que los consumidores puedan acceder a una mayor cantidad y variedad de productos (bienes y servicios) de mejor calidad y a un mejor precio; y que los competi- 
dores puedan ejercer su derecho a participar en los mercados en condiciones de libertad e igualdad dentro del marco de la Constitución y la ley.

Colombia, como la mayoría de países del mundo ha desarrollado su política de competencia a través de diferentes disposiciones legales. A partir de la liberación económica y la globalización que se dio en los años 90, la Constitución Política de 1991 consagró expresamente el derecho a la libre competencia económica en dos de sus artículos, a saber: el 88 y el 333.

Con la elevación a rango constitucional del concepto de la libre competencia se ha producido una acentuada proliferación normativa institucional que hace que exista un régimen general y una serie de regímenes especiales. Según el artículo 4 de la Ley 1340 de 2009, el Régimen General de la Libre Competencia se encuentra consagrado principalmente en la Constitución, la Ley 155 de 1959, el Decreto 2153 de 1992, la Ley 1340 de 2009 y demás normas concordantes. Dichas normas son aplicables a todos los sectores y todas las actividades económicas. Sin embargo, "en caso que existan normas particulares para algunos sectores o actividades, estas prevalecerán exclusivamente en el tema específico" (art. 4 ley 1340/2009). Así pues, constituyen regímenes especiales de la libre competencia aquellos aplicados al sector financiero y asegurador, al sistema de seguridad social en salud, al sistema de puertos y transportes, a los servicios públicos domiciliarios y a algunos servicios públicos no domiciliarios, entre otros.
Las normas sobre libre competencia en el sector del transporte se encuentran por fuera del régimen general. Dichas normas son las que se han mencionado a lo largo del presente trabajo, las cuales establecen de manera general que las únicas restricciones que se podrán hacer a la iniciativa privada son las que eviten la competencia desleal, el abuso de la posición de dominio o el monopolio, para garantizar la eficiencia del sistema de transporte, la competencia y el principio de seguridad.

Sin embargo, teniendo en cuenta el panorama actual, estos principios están siendo vulnerados por la legislación y el Gobierno al querer regular a Uber como una empresa prestadora de servicios de transporte igual al que prestan los taxis en nuestro país. En ese orden de ideas, Uber, por ser una plataforma tecnológica que presta un servicio de intermediación entre demandantes y oferentes del servicio de transporte, no puede ser catalogada ni regulada como una empresa prestadora del mencionado servicio. Por tanto, la lectura que han hecho las entidades estatales, específicamente el Ministerio de Transporte y la Superintendencia de Puertos y Transportes respecto de esta empresa, es incorrecta según nuestro parecer.

Si de lo que se trata es de proteger la libertad de empresa y de no exigir requisitos más allá de los legales y de los reglamentos respectivos de las empresas de transporte, las autoridades nacionales están cometiendo un error muy grave al pedirle a una plataforma tecnológica como Uber los requisitos de una empresa prestadora de servicios de transporte, imponiéndole unas 
cargas excesivas e imposibles de cumplir. Por su parte, si de lo que se trata es de proteger la competencia desleal y el abuso de la posición de dominio, las autoridades (como se ha dicho en reiteradas ocasiones) deberán reconsiderar su posición puesto que como se dijo anteriormente, Uber no compite con los taxis, y mucho menos, ostenta la posición de dominio en el mercado.

Catalogar como ilegal una modalidad de servicio (intermediación entre oferentes y demandantes) que no se encuentra regulada y es novedosa, va en contravía del principio de legalidad reconocido por el ordenamiento jurídico colombiano. En segundo lugar, tratar de enmarcar a esta empresa como prestadora de servicios de transporte cuando su objeto social se refiere a "la prestación de servicios por demanda de apoyo y soporte a personas naturales o jurídicas con dispositivos móviles o con aplicaciones basadas en desarrollos web" es un error garrafal. En tercer lugar, se ha visto que en las declaraciones públicas de la ministra de Transporte y el superintendente de Puertos y Transportes se busca favorecer solo a un sector interesado, el de los taxistas, dejando de lado otros actores como Uber, los conductores y los usuarios.

Ahora bien, lo anterior no excluye la posibilidad de que se fije un marco de funcionamiento donde se indique una serie de condiciones generales bajo las cuales Uber pueda desarrollarse y seguir operando legalmente en Colombia. Esto no solo permitiría la inclusión de nuevas tecnologías dentro del mercado, fomentaría en cierta medida la inversión extranjera y mejoraría las alternativas de movilidad en la ciudad, sino que también contribuiría a la consolidación de los principios del derecho de la competencia, a saber: libre participación de las empresas en el mercado, bienestar del consumidor y eficiencia económica.

Por otra parte, es necesario establecer que la expedición de normas y la regulación legislativa del tema, como se indicó previamente, se fundamenta principalmente en la protección al usuario, para garantizarle la prestación del servicio de transporte en condiciones de seguridad, acceso y calidad (art. 3 Ley 105 de 1993). Sin embargo, si bien existe dicha regulación, en la práctica no se ve reflejado el cumplimiento de esas garantías.

Uno de los principios que se ve más violentado en la práctica es el de la seguridad, el cual ha sido exaltado por la normativa de transporte. La calidad e idoneidad del vehículo representa una pieza clave en materia de seguridad. Las condiciones en las que se encuentren los vehículos son variables que cada vez se toman más en consideración por los demandantes del servicio. Muchos de los taxis no cuentan con cinturón de seguridad, con manivela para abrir la puerta o cerrar la ventana ni con air bags. Adicionalmente, son carros de avanzada edad o muy pequeños, los cuales son más propensos a sufrir mayores afectaciones en caso de accidentes automovilísticos. Por otra parte, los usuarios temen por su integridad personal debido al incremento de la inseguridad en la capital. Por todas estas razones, los demandantes del servicio se sienten cada vez más incómodos en los taxis, y 
lo que es peor, temiendo ser objeto de paseos millonarios, atracos, robos, etc.

Igualmente, la comodidad y la calidad son características del servicio de transporte que menciona el ordenamiento jurídico colombiano. Sin embargo, se reitera, estas no son cumplidas por todos los prestadores del servicio de taxi. En esta modalidad de transporte no se les ofrece a los usuarios elementos adicionales para tener un viaje más placentero. Este se restringe a la movilización del usuario de un lugar a otro. Por otra parte, el pago por este servicio debe hacerse en efectivo, lo cual en muchos casos se vuelve un problema porque el usuario no tiene monedas o billetes de baja denominación o porque el conductor no tiene cambio. Además, algunos de los vehículos no cumplen con condiciones de aseo pertinentes, debiendo el usuario someterse a malos olores y hasta residuos de basura.

Por último, en materia de accesibilidad se presentan varios inconvenientes para los demandantes del servicio tradicional de taxis, debido al tráfico de la ciudad en horas pico, los días Iluviosos, la distancia del recorrido y demás dificultades de movilidad que hacen que los taxistas limiten la oferta a su arbitrio. En muchas ocasiones los usuarios se encuentran con que los conductores no quieren llevarlos a su lugar de destino o simplemente no encuentran quien les preste el servicio.

En contraposición a lo anterior, Uber ha demostrado que la existencia de regulación legislativa frente a un tema no implica necesariamente la eficacia de dicha normativa. En ese sentido, la fuerza del mercado se ha encargado de sustituir los mandatos legales, al asegurar las condiciones de acceso, seguridad y calidad del servicio sin necesidad de norma expresa. En otras palabras, el mercado ha garantizado en mayor medida los derechos y las prerrogativas de los demandantes del servicio, asegurando mejores condiciones de calidad, acceso y seguridad, sin necesidad de una ley escrita que, en la práctica, se vuelve obsoleta.

Para concluir, podemos decir que Uber ha demostrado que el mercado y la libre competencia están en capacidad de crear servicios de calidad en el tema de transporte individual de pasajeros. La exclusión de Uber del mercado contribuiría a que el oligopolio que actualmente existe adquiera un mayor poder de mercado y siga generando pérdidas de eficiencia económica. Por esta razón, es necesario establecer un marco general que permita a los vehículos de servicio especial, a través de la aplicación Uber, competir con los vehículos que prestan el servicio de transporte individual de pasajeros en vehículos taxi.

\section{Referencias}

1. A former Student. (Marzo, 2014). Ubercompetitive: the ride-sharing platform war gets aggressive. Obtenido de: plataformeconomics.org: $\quad$ http://platformeconomics. org/2014/03/uber-competitive-ride-sharing-platform-war-gets-aggressive/

2. Asociación Bancaria y Entidades Financieras de Colombia. (2015). Informe trimestral de 
inclusión financiera. Cifras a 2014. Obtenido de asobancaria: http://www.asobancaria. com/portal/pls/portal/docs/1/4484750. PDF

3. Ayalde Lemos. V. (15 de diciembre de 2015). Uber: competencia entre plataformas, innovación y política económica Colombia. Recuperado de: http://lalibrecompetencia. com/2015/02/05/uber-competencia-entreplataformas-innovacion-y-politica-economica-colombiana/

4. Bobbio, N. (2007). Teoría general del derecho. Bogotá: Temis.

5. California Public Utilities Comission. (s. f.). Transportation Network Companies. Recuperado de: http://www.cpuc.ca.gov/PUC/ Enforcement/TNC/

6. Cámara de Comercio de Bogotá D. C. y Universidad de los Andes. (2014). Observatorio de Movilidad. Reporte Anual de Movilidad 2013. (No. 7).

7. Constituyente. (1991). Constitución Política de Colombia. Bogotá: Editorial Legis.

8. Contraloría de Bogotá D. C. (2005). El transporte público colectivo, individual y masivo de pasajeros, el transporte intermunicipal y las terminales satélites en Bogotá. Bogotá: Autor.

9. Corte Constitucional. Sentencia C-265 de 1994. (M. P.: A. Martínez; junio 2 de 1994).
10. Corte Constitucional de Colombia. Sentencia C-033 de 2014 (M. P.: Nilson Pinilla Pinilla; enero 29 de 2014).

11. Decreto 172 de 2001. Por el cual se reglamenta el Servicio Público de Transporte Terrestre Automotor Individual de Pasajeros en Vehículos Taxi. Febrero 5 de 2001. Obtenido de alcaldiabogota: http://www.alcaldiabogota.gov.co/sisjur/normas/Norma1. jsp?i=4309

12. Decreto 174 de 2001 [Presidencia de la República]. Por el cual se reglamenta el servicio público de transporte terrestre automotor especial. Febrero 5 de 2001. Obtenido de alcaldiabogota: http://www.alcaldiabogota. gov.co/sisjur/normas/Norma1.jsp?i=4310

13. Decreto 348 de 2015 [Ministerio de Transporte]. Por el cual se reglamenta el servicio público de transporte terrestre automotor especial y se adoptan otras disposiciones. Febrero 25 de 2015. Obtenido de wp.presidencia: http://wp.presidencia.gov. co/sitios/normativa/decretos/2015/Decretos2015/DECRETO\%20348\%20DEL\%20 25\%20DE\%2OFEBRERO\%20DE\%202015. pdf

14. El Espectador. (Marzo 13 de 2015). Usuarios convocan a "día de no taxi" por redes sociales. Obtenido de El Espectador: http:// www.elespectador.com/noticias/bogota/ usuarios-convocan-dia-de-no-taxi-redes-sociales-articulo-549229 
15. El Tiempo. (Diciembre 9 de 2008). Los taxis, símbolos de historia, cultura y sociedad, fueron protagonistas en el Salón de París. Obtenido de El Tiempo: http://www.eltiempo. com/archivo/documento/CMS-4713109

16. El Tiempo (Noviembre 23 de 2014). Servicios como Uber son ilegales, declara el Ministerio de Transporte. Obtenido de El Tiempo: http://www.eltiempo.com/tecnosfera/ novedades-tecnologia/servicios-como-uberson-ilegales-declara-el-ministerio-de-transporte/14869039

17. El Tiempo. (Enero 9 de 2015). En Colombia hay 14,4 millones de usuarios de "smartphones". Obtenido de El Tiempo: http://www. eltiempo.com/tecnosfera/novedades-tecnologia/colombia-el-tercer-pais-de-america-latina-con-mayor-numero-smartphones-/15066597

18. El Tiempo. (Marzo 12 de 2015). Video prende polémica entre Uber, taxistas y Gobierno. Obtenido de El Tiempo: http://www. eltiempo.com/bogota/uber-en-colombiavideo-de-ministra-de-transporte-con-taxistas/15384860

19. El Tiempo. (Marzo 13 de 2015). Uber pide pista de diálogos para regular transporte de lujo. Obtenido de El Tiempo: http://www. eltiempo.com/bogota/uber-en-colombiaempresa-pide-pista-en-dialogo-de-nueva-regulacion-para-transporte-de-lujo/15388397
20. Evans, D. (Marzo de 2014). Plataform Economics: Essays on Multi-sided Businesses. Lexington, Kentucky: CreateSpace. Obtenido de https://www.competitionpolicyinternational. com/assets/Hot-Tubs/SSRN-id1974020.pdf

21. Krugman, P. R. y Wells, R. (2006). Introducción a la economía: microeconomía. BarceIona: Editorial Reverté S. A.

22. Krugman, P. R., Wells, R. y Olney, M. L. (2008). Fundamentos de economía. BarceIona: Editorial Reverté S. A.

23. Laserna, D. (6 de agosto de 2014). Chambonada y marrulla: la saga de los cupos de taxi en Bogotá. Recuperado de: http://www.elespectador.com/noticias/actualidad/vice/ chambonada-y-marrulla-saga-de-los-cuposde-taxis-bogota-articulo-508988

24. Ley 105 de 1993. Por medio de la cual se dictan disposiciones básicas sobre transporte, se redistribuyen competencias y recursos entre la Nación y las Entidades Territoriales, se reglamenta la planeación en el sector transporte y se dictan otras disposiciones. Diciembre 30 de 1993. Obtenido de alcaldiabogota: http://www.alcaldiabogota.gov. co/sisjur/normas/Norma1.jsp?i=296

25. Ley 256 de 1996. Por la cual se dictan normas sobre competencia desleal. Enero 15 de 1996. DO n. ${ }^{\circ}$ 42692. Obtenido de alcaldiabogota: http://www.alcaldiabogota.gov. co/sisjur/normas/Norma1.jsp?i=38871 
26. Ley 336 de 1996. Por la cual se adopta el estatuto nacional de transporte. Diciembre 20 de 1996. DO n. ${ }^{\circ}$ 42948. Obtenido de alcaldiabogota: http://www.alcaldiabogota. gov.co/sisjur/normas/Norma1.jsp?i=346

27. Ministerio de Tecnologías de la Información y las Comunicaciones. (2015). Boletín trimestral de las tic. Obtenido de colombiatic: http://colombiatic.mintic.gov.co/602/articles-8598_archivo_pdf.pdf

28. Ministerio de Transporte de Colombia. (s. f.). Aspectos de la situación actual del aseguramiento en el Sector del Servicio Público de Transporte Terrestre Automotor (delimitación, definición y detalle de los aspectos que impliquen inconvenientes, gastos y sobrecostos subsanables, respecto de los cuales se presentan propuestas). Obtenido de mintransporte: https://www.mintransporte. gov.co/descargar.php?idFile $=9$

29. Nicholson, W. (2007). Teoría microeconómica. Principios básicos y ampliaciones. México D. F.: Editorial Thomson.

30. Organización para la Cooperación y Desarrollo Económicos [ocde]. (2014). Estudios de la ocde de las Políticas de Innovación: Colombia. Recuperado de: http://www.oecd. org/sti/inno/colombia-innovation-review-assessment-and-recommendations-spanish. pdf

31. Redacción de El País. (Marzo 30 de 2015). Con derecho de petición, piden regulación de plataforma Uber en Colombia. Recuperado de http://www.elpais.com.co/elpais/ cali/noticias/con-derecho-peticion-pidenregulacion-plataforma-uber-colombia

32. Rodríguez, A. y Acevedo, J. (2012). ¡Taxi! El modo olvidado de la movilidad en Bogotá. Bogotá: Ediciones Uniandes.

33. Salazar, J. (2001). Introducción al estudio del transporte. Bogotá: Universidad Externado de Colombia.

34. Semana. (Noviembre 29 de 2014). ¿Qué pasará con Uber en Colombia? Obtenido de Semana: http://www.semana.com/nacion/articulo/uber-que-pasara-en-colombia/410592-3

35. Sentencia 4230 de 2012 [Superintendencia de Industria y Comercio. Delegatura para Asuntos Jurisdiccionales]. Superintendente delegado: Adolfo León Varela Sánchez; julio 31 de 2012. Obtenido de sic.gov: http:// www.sic.gov.co/drupal/sites/default/files/ files/sentencia\%20de\%20competencia\%20 desleal/Sentencia_4230_2012.pdf

36. Superintendencia de Puertos y Transportes de la República de Colombia. (Julio 9 de 2014). Circular Externa n. ${ }^{\circ} 00000013$. Asunto: cumplimiento de las empresas de servicio público de transporte terrestre automotor especial.

37. Superintendencia de Puertos y Transportes de la República de Colombia. (Diciembre 30 
de 2014). Circular Externa No. 00000024 Asunto: adopción medidas frente al transporte informal.
38. Transportation Network Companies (s. f.). Obtenido de California Public Utilities Commission: http://www.cpuc.ca.gov/PUC/Enforcement/TNC/ 